\title{
Lumen
}

Selected Proceedings from the Canadian Society for Eighteenth-Century Studies

\section{Le modèle antique et la transformation de l'idée de patrimoine sous la Révolution française}

\section{Emmanuelle Hénin}

Volume 26, 2007

Imitation et invention au siècle des Lumières

Imitation and Invention in the Eighteenth Century

URI : https://id.erudit.org/iderudit/1012067ar

DOI : https://doi.org/10.7202/1012067ar

Aller au sommaire du numéro

Éditeur(s)

Canadian Society for Eighteenth-Century Studies / Société canadienne d'étude du dix-huitième siècle

ISSN

1209-3696 (imprimé)

1927-8284 (numérique)

Découvrir la revue

Citer cet article

Hénin, E. (2007). Le modèle antique et la transformation de l'idée de patrimoine sous la Révolution française. Lumen, 26, 159-189.

https://doi.org/10.7202/1012067ar

Copyright (c) Canadian Society for Eighteenth-Century Studies / Sociéte canadienne d'étude du dix-huitième siècle, 2007
Ce document est protégé par la loi sur le droit d'auteur. L'utilisation des services d'Érudit (y compris la reproduction) est assujettie à sa politique d'utilisation que vous pouvez consulter en ligne.

https://apropos.erudit.org/fr/usagers/politique-dutilisation/ 


\section{Le modèle antique et la transformation de l'idée de patrimoine sous la Révolution française}

L'imitation, dans les arts du dessin, ne saurait jamais se séparer de l'invention'.

Depuis la Renaissance, l'idée de patrimoine est intimement liée au modèle antique. $\mathrm{D}^{\prime}$ abord parce que cette idée naît avec l'humanisme, la redécouverte de Rome, alors seul patrimoine, et la conscience d'un passé révolu. Dans les années 1420, sous Eugène IV, les humanistes appellent à la conservation des monuments romains (appels largement restés lettre morte), aboutissant à une lettre de Pie II en 1462, un des premiers textes proposant des mesures de conservation du patrimoine ${ }^{2}$. Dès lors, le patrimoine se lie au modèle antique à travers l'idée d'émulation: la conservation n'est pas vouée à la contemplation, mais doit fournir

1 Antoine Quatremère de Quincy, Considérations sur les arts du dessin, Paris, Desenne, 1791 [Genève, Slatkine Reprints, 1970, introduction, p. xi].

2 Cette lettre incitant à veiller avec le même soin sur les monuments chrétiens et paiens est citée plus loin, note 26. Sur l'histoire de la conservation du patrimoine, voir Françoise Choay, L'allégorie du patrimoine, Paris, Seuil, coll. «La couleur des idées», 1992 ; François Hartog, Régimes d'historicité, Paris, Seuil, coll. «La librairie du XXI $\mathrm{I}^{\mathrm{e}}$ siècle», 2003, chapitre "Patrimoine et présent»; et Alain Schnapp, La conquête du passé. Aux origines de l'archéologie, Paris, Carré, 1993. Sur l'idée de patrimoine, voir l'introduction au livre de Dominique Poulot, «Surveiller et s'instruire» : la Révolution française et l'intelligence de l'héritage historique, Oxford, Voltaire Foundation, coll. "Studies on Voltaire and the Eighteenth Century», 1996 : l'historien montre comment le patrimoine se confond pendant la période révolutionnaire avec une "pensée monumentale» obsédée par le souci de transmission à la postérité, sans définir le contenu réel de ce patrimoine. Enfin, pour une définition strictement juridique du patrimoine sous l'Ancien Régime, voir Robert W. Schleller, «La notion de patrimoine artistique et la formation du musée au XVIII ${ }^{\mathrm{e}}$ siècle», dans Édouard Pommier (dir.), Les musées en Europe à la veille de l'ouverture du Louvre, Paris, Klincksieck, 1995, 111-124. 
des modèles, se perpétuer dans un art vivant, à travers la résurrection des formes ${ }^{3}$. Cette émulation joue un rôle central dans l'évolution des arts, dans l'Italie renaissante et la France du XVII ${ }^{e}$ siècle, où les peintres sont envoyés à Rome pour voir les antiques, à moins que celles-ci ne soient copiées pour être envoyées à Paris. La Révolution lie indissolublement les deux domaines, conservation et création ; partout en Europe, la diffusion du style néoclassique va de pair avec l'ouverture de musées, destinés aux artistes autant qu'au grand public ${ }^{4}$. David est à la fois le premier grand peintre néoclassique, le co-fondateur du Louvre et l'organisateur des fêtes célébrant son ouverture en 1793.

Ces initiatives semblent consacrer la formation lente de l'idée de patrimoine et pourtant, celle-ci subit une rupture au moment de la Révolution : le patrimoine des Lumières s'incarnait dans l'héritage antique, situé géographiquement à Rome et dont toute l'Europe était cohéritière, et dans une continuité historique. Au contraire, la Révolution fait table rase du passé et revendique une singularité nationale, qui la rend héritière privilégiée du patrimoine antique, d'abord sous forme métaphorique, puis très concrètement, par la saisie des antiques romaines pendant la campagne d'Italie. Jamais l'Antiquité n'a été autant présentée en modèle à imiter, à la fois politique et esthétique (aboutissement conjugué de la philosophie politique des Lumières et de l'esthétique de la belle nature); et jamais on n'a autant ressenti l'urgence d'inventer une histoire nouvelle, qui efface celle des tyrans nationaux et dépasse, en s'y référant, l'histoire antique. La Révolution, tout en se voulant commencement absolu, ne cesse $d$ 'invoquer le modèle antique comme le mythe d'un âge d'or.

La Révolution tient donc sur le patrimoine et le modèle antique un discours radicalement innovant, en continuité apparente avec la Renaissance, mais, en réalité, en rupture sur trois points : la conception du temps (puisque le modèle antique n'est plus objet d'une renovatio, mais d'une régénération); l'espace du patrimoine, qui se trouve d'autorité transporté de Rome et $\mathrm{d}^{\prime}$ Athènes ${ }^{5}$ à Paris ; et la doctrine de l'imitation

3 Sur les collections et les moulages d'antiques, voir Francis Haskell et Nicholas Penny, Taste and the Antique : the Lure of Classical Sculpture, 1980 ; traduction française : Pour l'amour de l'antique: la statuaire gréco-romaine et le goût européen : 1500-1900, trad. Fr. Lissarague, Paris, Hachette, coll. «Bibliothèque d'archéologie», 1988.

4 Ils ont des jours d'ouverture différents au Louvre : les copistes sont admis les cinq premiers jours de chaque décade et le public les trois suivants, les deux derniers servant au nettoyage.

5 Avant de commencer, il importe en effet de préciser de quelle Antiquité on parle : grecque ou romaine (sans parler de l'Égypte, qui ne joue pas un rôle aussi prépon- 
de la belle nature, qui est mise à distance et reformulée. Chaque fois, l'invention passe par l'imitation de l'antique, mais cette imitation est entendue dans un sens nouveau.

\section{L'Antiquité ou le temps du patrimoine : rénovation et régénération}

Penser le patrimoine suppose un rapport à l'héritage et au temps fondamentalement différent pour les humanistes et pour les hommes de la Révolution. Au temps cyclique de la renovatio et de la plenitudo temporum s'oppose un temps de rupture inaugural, indéfiniment réitérable : on ne parle plus de rénovation, mais de régénération, même si d'autres termes sont communs, qui évoquent une renaissance puisée dans les ressources du passé : résurrection, restitution. Toutefois, la Révolution se veut aussi une re-naissance, le début d'une nouvelle ère, et la Renaissance une ré-volution, un retour à l'ordre ancien, selon le sens ancien du mot employé par les philosophes dès le milieu du XVIII siècle $^{6}:$ les termes sont à première vue interchangeables.

dérant) ? Les Français (dans le discours esthétique, pas juridique) ont tendance à confondre Grecs et Romains sous le nom d' "Anciens», dans une vision plutarchéenne (contrairement aux Allemands). Deux Antiquités, deux modèles : Rome était le grand modèle des humanistes depuis le $X V^{e}$ siècle et, par la richesse de ses ruines et son rôle de capitale de la chrétienté, un lieu de pèlerinage sur les traces de l'histoire et des civilisations ; puis, à partir de 1750 et surtout des Pensées sur l'imitation de Winckelmann (1755), la Grèce passe au premier plan comme modèle de liberté politique et modèle originaire (tandis qu'on soulignait auparavant l'héritage des Égyptiens, des Phéniciens, etc.). L'idée d'une singularité grecque émerge dans les 1760 et 1770, avec l'exploration de Paestum. Dès lors, la hiérarchie entre Grèce et Rome est très nette, comme le montre l'article "Grèce» de l'Encyclopédie : "Les Romains en comparaison des Grecs, eurent peu de goût pour les arts ; ils ne les ont aimés, pour ainsi dire, que par air et par magnificence [...].» En outre, Rome est un modèle politique ambigu, et impose de faire le tri : aux yeux des philosophes, elle est d'un côté le règne des tyrans Néron et Caligula et le siège de la papauté; de l'autre, la fondatrice d'une république chassant la tyrannie et inventant une bonne législation. Géographiquement, cependant, Rome demeure le lieu d'un musée des antiques ; c'est par elle que passe la "chaîne d'or attachée à la Grèce» (Watelet), $c^{\prime}$ est là qu'on peut admirer les statues grecques (et surtout leurs copies romaines). Enfin, la référence à Rome reprend une place importante en 1796-1798, après la campagne d'Italie : on s'autorise du précédent romain pour piller la Ville, comme Rome a jadis dépouillé la Grèce !

6 Sur l'histoire de ce mot (et sur bien d'autres points du présent article), voir le très complet ouvrage de Chantal Grell, Le dix-huitième siècle et l'Antiquité en France: 1680-1789, Oxford, Voltaire Foundation, coll. «Studies on Voltaire and the Eigh- 


\section{1) La rénovation du passé}

La Renaissance considère l'Antiquité moins comme un passé que comme une sorte d'éternel toujours présent. Ou plutôt, en reléguant pour la première fois l'Antiquité dans les profondeurs du passé, elle se donne les moyens de réfléchir sur les conditions de sa réactualisation et de mettre en perspective le présent lui-même. La renovatio humaniste est un retour au passé qui accomplit la plénitude du temps, invoquée par les humanistes florentins au $X V^{\mathbb{E}}$ siècle dans les arts et les lettres, et culminant à Rome sous Jules II (1503-1513) ${ }^{7}$, qui entend restaurer tout l'héritage politique et culturel de la Rome ancienne: le livre fondateur de l'archéologie moderne s'appelle précisément Roma instaurata, «Rome restaurée» (Flavio Biondo, 1450) ${ }^{8}$. Cette renovatio n'est pas une copie, mais une conversion de l'héritage païen, de la Rome antique à la Rome chrétienne : la papauté est désormais le centre d'un ordre universel, comparable à celui de l'Empire romain. Depuis Pétrarque, la pensée humaniste se fonde sur ce parallélisme constant et fait l'économie d'une démarche historique : l'histoire est conçue comme une succession de cycles où chaque apogée renouvelle le précédent, après une période obscure ${ }^{9}$. En un sens, les Révolutionnaires renouent avec ce discours :

teenth Century», 1995, chapitre "Le sens de l'histoire: les révolutions», vol. II, p. 1039-1048 ; ainsi que Alain Rey, Révolution, histoire d'un mot, Paris, Gallimard, coll. «Bibliothèque des histoires», 1989. Ce concept d'origine astronomique évoque le retour d'un événement observé et implique l'idée de rupture (ainsi dans le domaine de la mécanique horlogère, de la médecine, de l'histoire naturelle). En histoire, les Français l'utilisent pour désigner tout changement de régime (voir l'article de Jaucourt dans l'Encyclopédie : "Révolution signifie un changement considérable arrivé dans le gouvernement d'un État»), et renvoie à deux modèles : anglais (la Révolution de 1688) et romain, les historiens romains associant le terme à la décadence et au déclin (voir Furetière, Trévoux). La notion de révolution s'impose donc à travers le paradigme de l'histoire ancienne, et avec une connotation négative. Quant à la Renaissance, si le concept historiographique en remonte à Burckhardt ( $\mathrm{La}$ civilisation de la Renaissance en Italie, 1860), la conscience du phénomène et le mot rinascità sont présents dès les écrits du début du $\mathrm{XV}^{\mathfrak{e}}$ siècle, chez Lorenzo Valla ou Alberti.

7 Voir André Chastel, Art et humanisme à Florence au temps de Laurent le magnifique, Paris, PUF, 1959 ; et Mythe et crise de la Renaissance, Genève, Skira, 1989.

8 Flavio Biondo, Roma instaurata, Rome, 1450 [Rome restaurée, trad. et éd. par Anne Raffarin-Dupuis, Paris, Belles-Lettres, 2005].

9 Pétrarque est le premier à prendre conscience de la césure entre temps anciens (antiquae) et temps nouveaux, depuis le christianisme (novae), alors que les théologiens médiévaux promouvaient une conception linéaire du temps, dans une continuité (ainsi Augustin dans la Cité de Dieu), théorie des six âges du monde. En outre, 
les hommes politiques (Robespierre ou Saint Just) en appellent à une résurrection de l'antique, s'identifient à Brutus, ne cessent de comparer le destin de la France à celui de la Grèce et de Rome. Et dans les deux cas, le modèle antique est largement mythique, investi par l'idéologie : à la Renaissance, il est surtout moral (mêlé d'aspirations patriotiques, culturelles et politiques), tandis qu'il est politique (et, au premier chef, juridique et institutionnel) sous la Révolution. Enfin, cette conception conjugue l'idée de modèle avec le mythe de l'origine, l'Antiquité donnant un modèle de rupture ; elle fournit au législateur des modèles intemporels de commencements absolus, avec les débuts de la démocratie athénienne ou de la République romaine, et finalement présuppose un refus de considérer la continuité historique, une pure et simple élision du temps : "Le monde est vide depuis les Romains", s'écriait SaintJust $^{10}$. Cette attitude rappelle le refus de la Renaissance et des siècles classiques de considérer les âges obscurs autrement que comme une parenthèse nulle et non avenue entre l'Antiquité et sa restauration.

Mais la Révolution, héritière des Lumières, hérite aussi d'une philosophie moderne du progrès conçu comme un temps ouvert : si l'histoire est faite de cycles, alternant apogées et déclins, ces cycles sont eux-mêmes inscrits dans un progrès continu, dont le mouvement évoque plutôt la figure d'une spirale. Le présent n'est pas plénitude et aboutissement, mais le début d'une histoire nouvelle, la promesse d'une régénération (le mot est omniprésent dans les textes politiques et artistiques ${ }^{11}$ ) qui atteindra toute $\mathrm{l}^{\prime}$ Europe à partir du modèle français ${ }^{12}$. L'Antiquité est à

Pétrarque fait de l'époque post-antique un âge de ténèbres, qui commence à la naissance du Christ, inversant tous les schémas. Voir sur ce point Sabine ForeroMendoza, Le temps des ruines. Le goût des ruines et les formes de la conscience historique à la Renaissance, Paris, Champvallon, 2002.

10 Saint-Just, Discours du 11 germinal an II, cité par François Hartog, «La Révolution française et l'Antiquité. Avenir d'une illusion ou cheminement d'un quiproquo ?», La pensée politique, 1, 1993, 30-61.

11 Voir Mona Ozouf et François Furet (dir.), Dictionnaire critique de la Révolution française, Paris, Flammarion, 1988. Ce mot issu de la philosophie des Lumières renvoie au mythe de l'homme nouveau ; il est employé dès 1789 dans les pamphlets réclamant la tenue d'États généraux, et reste marqué par une ambiguïté jamais levée : la régénération doit-elle être instantanée ou progressive et programmatique? Dans la mesure où le discours sur les arts met en son centre les préoccupations politiques, il s'empare systématiquement du terme pour désigner la mission de l'art, dans son lien avec la société : les arts (qui avaient «dégénéré» sous l'Ancien Régime), régénérés par le nouveau contexte politique, vont à leur tour régénérer la morale des citoyens.

12 Boissy d'Anglas, Essai sur les fêtes nationales (mars 1794), Paris, Imprimerie Poly- 
la fois mémoire et prophétie : «Le monde est vide depuis les Romains ; et leur mémoire le remplit, et prophétise encore la liberté ${ }^{13}{ }^{\prime}$.

Ainsi, la renovatio ne consiste pas à connaître et à exhumer le passé (pour en tirer une morale à l'usage du présent, comme le faisait Pétrarque), mais à le ressusciter dans les institutions (pour en tirer une politique active), et c'est précisément l'utopie que Chateaubriand (Essai sur les Révolutions, $1797^{14}$ ) et les Idéologues ${ }^{15}$ dénoncent comme une conception fallacieuse de l'histoire, une utopie de résurrection ou de révolution, au sens originel du terme : l'illusion d'un retour à l'âge d'or. Le passé surgit dans le présent de manière fulgurante ; $l$ Antiquité est choisie comme un modèle de commencement; on se réfère sans cesse à la chute des rois et aux débuts de la République romaine, à la chute des tyrans d'Athènes et aux débuts de la démocratie (par les lois de Solon), et à la constitution de Lycurgue à Sparte. Alors que la restitutio humaniste ouvrait sur la plénitude du présent, la régénération révolutionnaire ne se justifie que dans la perspective du futur. Elle ouvre sur un avenir incertain, même si tout est fait pour conjurer l'incertitude et donner des signes de clôture du présent, notamment en écrivant l'histoire de la Révolution au fur et à mesure. L'instauration d'une ère

glotte, an II, p. 44-45 : «Le système politique de l'Europe a dû nécessairement être changé par la révolution française, et il le sera, sans doute encore, par les autres révolutions qui vont régénérer incessamment les empires qui nous avoisinent».

13 Saint-Just, loc. cit. ; l'article de François Hartog est fort éclairant sur la conception révolutionnaire de l'histoire.

14 Chateaubriand, Essai sur les Révolutions (1797), éd. Maurice Regard, dans Essai sur les révolutions, Le Génie du christianisme, Paris, Gallimard, coll. «Bibliothèque de la Pléiade», 1978, livre I, ch. 17, p. 90 : «Un trait distinctif de notre révolution, c'est qu'il faut admettre la voie spéculative et les doctrines abstraites pour infiniment dans ses causes. Elle a été produite en partie par des gens de lettres qui, plus habitants de Rome et d'Athènes que de leur pays, ont cherché à ramener dans l'Europe les mœurs antiques». Tout l'Essai s'applique à opposer les caractères des nations antiques et modernes, fondé sur cet amer constat d'anachronisme: «Le mal, le grand mal, c'est que nous ne sommes point de notre siècle» (Introduction, p. 42).

15 Tel Volney, Leçons d'histoire à l'École normale, 1795 : ouvrage élémentaire, contenant des vues neuves sur la nature de l'histoire, sur le degré de confiance et le genre d'utilité dont elle est susceptible; sur l'abus de son emploi dans l'éducation de la jeunesse; et sur le danger de ses comparaisons et de ses imitations généralement vicieuses en matière de gouvernement. La $6^{\mathrm{e}}$ leçon est une attaque en règle contre la «secte nouvelle» qui a «juré par Sparte, Athènes et Tite-Live». Tel encore Benjamin Constant dans sa conférence «De la liberté des Anciens comparée à celle des Modernes", 1819, qui dénonce le piège de la nostalgie: "lorsqu'on se livre à ces regrets, il est impossible de ne pas vouloir imiter ce qu'on regrette». Textes cités par François Hartog, art. cit. Par la suite, cette critique de la Révolution comme imitation devient un topos, repris jusqu'à Marx. 
nouvelle est symboliquement marquée par la création du calendrier révolutionnaire, coïncidant avec l'instauration de la République (le $1^{\mathrm{er}}$ vendémiaire an I) : on écarta alors la proposition d'intégrer le passé en comptant à reculons, par une "computation rétrograde», devant la nécessité plus grande de souligner la rupture, la conviction de vivre une histoire exceptionnelle ${ }^{16}$. Ainsi les fêtes révolutionnaires se donnentelles pour but la commémoration non de l'héritage lointain, mais du seul acte fondateur, dont elles fixent le souvenir; si elles contiennent une représentation d'avenir, ce n'est pas un avenir ouvert, mais exclusivement répétitif. Elles isolent certains événements en présentant une série de tableaux allégoriques, niant l'histoire au profit d'une typologie abstraite des vertus et des vices.

Le renouveau des circonstances exceptionnelles où s'est développé l'art grec doit donc permettre une régénération des arts, passant par deux moyens : conservation et création, indissolublement liées dans la politique des arts, puisque le patrimoine n'est conservé qu'en vue de nourrir l'art du futur. Le concept de régénération articule passé et futur.

\section{2) Régénération et conservation}

La Terreur encourage un vandalisme officiel, aboutissement logique de son utopie d'une violence refondatrice; mais l'excès de violence déclenche paradoxalement la première politique active et cohérente de conservation du patrimoine, promue par la Convention comme la clef du processus de régénération - là où les décrets précédents étaient toujours restés lettre morte ${ }^{17}$. Comment dépasser la contradiction entre

16 Voir Mona Ozouf, La fête révolutionnaire : 1789-1799, Paris, Gallimard, coll. «Bibliothèque des histoires", 1976.

17 Pour l'histoire précise du vandalisme et de la politique du patrimoine sous la Révolution, voir Édouard Pommier, L'art de la liberté : doctrines et débats de la Révolution française, Paris, Gallimard, coll. «Bibliothèque des histoires », 1991 ; Dominique Poulot, Musée, nation, patrimoine, 1789-1815, Paris, Gallimard, coll. « Bibliothèque des histoires ", 1997 ; et D. Rabreau et B. Tollon (dir.), Le progrès des arts réunis, 17631815 : mythe culturel des origines de la Révolution à la fin de l'Empire? Actes du Colloque international d'histoire de l'art, Bordeaux-Toulouse, 22-26 mai 1989, Bordeaux, CERCAM, 1992, notamment l'article d'Édouard Pommier, «Les arts en révolution, ou le patrimoine de la liberté», 3-13. Les destructions iconoclastes vont de pair avec les premières mesures effectives de conservation, prises au moyen d'une série de décrets entre 1790 et 1795 . Des débats apparaissent dès 1790 entre conservation et iconoclasme (ainsi, en juin 1790, le sculpteur Caffieri s'oppose à la destruction de la statue de la Place des Victoires, prônée par David). Le décret du 3 brumaire an II 
rénovation et retour aux origines, iconoclasme et patrimoine ? La solution consiste à conserver les monuments du despotisme comme un héritage artistique - et un témoignage d'une époque où les arts étaient asservis aux tyrans. La Révolution a pour mission de régénérer les arts par l'imitation et par la liberté indispensable à leur épanouissement, selon la vulgate diffusée par Winckelmann ${ }^{18}$ et par son disciple français, Quatremère de Quincy, dans ses Considérations sur les arts du dessin ${ }^{19}$. Pendant toute la Révolution, l'alliance de l'art et de la liberté s'unit au topos de l'utilité sociale et politique de l'art, au point que le discours esthétique disparaît souvent sous le politique. Ainsi chez David, qui affiche dans ses discours une conception contradictoire du patrimoine : il veut à la fois trier le patrimoine selon des critères esthétiques et idéologiques, et créer un patrimoine-mémorial ${ }^{20}$. À ce «patrimoine

(13 octobre 1793) interdit de détruire, mutiler, enlever sous prétexte de détruire les monuments de la féodalité. À partir de la crise iconoclaste de l'été 1792, des mesures plus précises seront prises pour réagir au vandalisme, notamment grâce à la création de la Commission du Muséum par Roland.

18 Voir la phrase ouvrant le chapitre sur la Grèce de la Geschichte, op. cit. : «Du point de vue du régime et du gouvernement, la liberté est la cause privilégiée de l'excellence des arts en Grèce». C'est parce que les Grecs ont su porter la liberté à son apogée que les arts y ont fleuri ; et malgré tout leur zèle, les Romains n'y arrivent pas. En réalité, selon Élisabeth Décultot, cette équation entre art et liberté vient de $\mathrm{l}^{\prime}$ Angleterre de la fin du XVII ${ }^{e}$ et du XVIII ${ }^{\mathrm{e}}$ siècle. Winckelmann est passionné par la Révolution anglaise, surtout Shaftesbury, Thomas Gordon, Blackwell, Wotton. Voir Élisabeth Décultot, Johann Joachim Winckelmann. Enquête sur la genèse de l'histoire de l'art, Paris, PUF, coll. «Perspectives germaniques», 2000.

19 Winckelmann rencontre un succès immédiat, dès avant la Révolution : l'année même de leur publication, deux traductions des Gedanken paraissent en moins d'un an, en 1755 ; il en va de même pour l'Histoire de l'art de l'Antiquité, publiée en 1764 et traduite en 1766. Par son analyse des conditions politiques du développement de l'art grec, cet auteur permet le passage de l'esthétique à la politique, et entre ainsi dans le dessein de la politique artistique de la Révolution. Mais l'idée que la Grèce est un modèle insurpassable et le lien entre l'art et la liberté étaient déjà établis par Jaucourt dans deux articles de l'Encyclopédie: «Grecs» et «Histoire de l'art chez les Grecs» (1776). C'est donc tout naturellement que Jansen, en 1791, invoque la liberté des Grecs pour appeler à une «régénération» de l'art français. Voir à ce sujet François Hartog, «Faire le voyage d'Athènes : Johann-Joachim Winckelmann et sa réception française», dans Jackie Pigeaud et Jean-Paul Barbe (dir.), Winckelmann et le retour à l'antique, Actes du colloque, 9-12 juin 1994, Nantes, Université de Nantes, $1995,127-143$.

20 Voir Édouard Pommier, «David et le patrimoine», dans Régis Michel (dir.), David contre David, Paris, La Documentation française, coll. "Conférences et colloques (Musée du Louvre)», 1993, 555-587. David oscillerait entre deux dangers : l'utopie d'une conservation universelle et perpétuelle dans un «superbe muséum», et l'uto- 
national» (selon l'expression inventée par Puthod de Maisonrouge en 1790), l'Antiquité offre un point de comparaison : certes, les ruines suscitent une méditation amère sur la destruction des Empires (comme à la Renaissance, chez Pétrarque ou Montaigne ${ }^{21}$ ), mais elles fournissent aussi l'image de monuments à l'épreuve du temps, comme le souligne le député Kersaint dans son Discours sur les monuments publics (1792), qui plaide pour la création d'un Muséum français au Louvre :

Les Grecs et les Romains ne sont plus : pourquoi les Français voudraient-ils toujours être?

Les monuments sont les témoins irréprochables de l'histoire ; sans leurs ruines augustes tout ce qu'elle nous a transmis des Grecs et des Romains ne nous eût paru qu'une fable.

Que les Français songent à la postérité2 ${ }^{22}$.

L'émotion devant les ruines est encore invoquée par Grégoire dans son Premier rapport sur le vandalisme (1794) pour justifier la nécessité de conserver l'héritage ; et dix ans plus tard, au cours d'une promenade imaginaire sur l'Acropole, Émeric-David fait l'éloge du monument, qui immortalise l'histoire de la nation, excite l'admiration des contemporains et de la postéritée $e^{23}$. La Révolution hérite de l'idée de monument élaborée par la Renaissance. Celle-ci avait conféré le statut de monument à tous les édifices anciens (et non seulement aux monuments «intentionnels», construits dans un but commémoratif) comme témoignages d'un passé, mais la valeur esthétique l'emportait encore

pie d'une régénération par la destruction des symboles et la manipulation du passé au nom d'une idéologie tendant à la barbarie.

21 Sur ce sujet, voir Sabine Forero-Mendoza, Le temps des ruines, op. cit.

22 Armand-Guy Kersaint, "Avertissement», Discours sur les monuments publics, prononcé au Conseil du département de Paris, le 15 décembre 1791, Paris, Didot aîné, 1792.

23. Recherches sur l'art statuaire considéré chez les anciens et chez les modernes, Paris, Nyon, An XIII [1805], p. 147 : «Quand les artistes reçoivent des gouvernements la noble mission de contribuer à maintenir la morale publique, d'immortaliser par des monuments l'histoire d'une nation entière, de faire aimer les lois ; l'idée qu'ils se forment à juste titre de l'importance de leurs chefs-d'œuvre, l'intérêt que le public prend à leurs succès, le jugement impartial qu'ils sollicitent et qu'ils appréhendent, tous ces motifs élèvent des génies ardents au-dessus d'eux-mêmes. Ce sont les grands sujets qui font naître les grandes pensées. Il faut exciter l'admiration de la génération présente ; il faudra étonner et émouvoir encore les générations à venir. L'artiste, son pays, son siècle même recevront du monument qui va s'élever, ou un long mépris ou une gloire immortelle : quelles causes d'émulation !» 
sur la valeur historique, qui s'affirme seulement au tournant des XVIII et XIX ${ }^{\mathrm{e}}$ siècles ${ }^{24}$. En outre, la valeur mémoriale du mot prévaut dans le lexique français, et le terme se spécialise dans le sens d'édifice seulement dans le courant du XVIII ${ }^{\mathrm{e}}$ siècle ${ }^{25}$.

$C^{\prime}$ est bien le propre du monument que de faire mémoire pour la postérité, d'être un trait d'union entre le passé et l'avenir : déjà Pie II, dans la première proposition de décret sur la conservation de monuments historiques (1462), disait que les ruines de Rome, tout en rappelant la précarité du présent, perpétuaient les monuments des vertus passées ${ }^{26}$. Mais en développant cet imaginaire monumental, la Révolution réduit le patrimoine à la question obsessionnelle de la transmission du passé au futur, sans jamais définir le contenu de ce qui est transmis ${ }^{27}$. Témoin de cette obsession, la méditation des peintres sur le thème des ruines futures, qui projettent un passé millénaire dans un futur utopique (ou uchronique, peut-être sous l'influence des uchronies littéraires),

24 Pour reprendre les analyses d'Aloïs Riegl, Das Moderne Denkmalkultus (Le culte moderne des monuments, Seuil, 1984), qui distingue trois catégories : 1) les monuments intentionnels (destinés à commémorer un événement) ; 2) les monuments historiques (renvoyant à un moment particulier) ; 3) les monuments anciens (toutes les créations de l'homme qui ont subi l'épreuve du temps).

25 Témoin le Dictionnaire de l'Académie (1694) : «Monument. Marque publique qu'on laisse à la postérité pour conserver la mémoire de quelque personne illustre ou de quelque action célèbre». Voir aussi A. Jourdan, Les monuments de la Révolution, 17701804. Une histoire de représentation, Paris, Honoré Champion, coll. "Les dix-huitièmes siècles ", 1997. L'historienne montre que le monument public a une dimension indissociablement mémorative et incitative, car il stimule par des textes et des figures exemplaires - ainsi du Panthéon, à la fois lieu de mémoire et d'émulation.

26 Pie II, Lettre pour que les édifices anciens de la ville et de son territoire ne soient pas détruits, 1462, citée par Alain Schnapp, La conquête du passé, op. cit., p. 338-339: "Comme nous désirons que la Ville notre Mère soit respectée dans sa dignité et sa splendeur, nous devons avant tout employer un soin vigilant non seulement à ce que les basiliques et les églises de la Ville ainsi que les lieux saints et consacrés, dans lesquels sont conservés de très nombreuses reliques de saints, soient maintenus et préservés dans leurs admirables édifices, mais encore à ce que les anciens et antiques édifices, ainsi que leurs vestiges, demeurent pour les générations futures, car ils apportent à la Ville son plus grand ornement et sa plus grande parure, et car [sic] ils se dressent en monuments des vertus anciennes et incitent à en perpétuer la gloire ; et, fait à prendre encore plus en considération, ces édifices et leurs vestiges permettent de mieux contempler la fragilité des œuvres humaines; que l'on ne se fie en rien aux œuvres humaines, puisque ces édifices dont nos Anciens pensaient qu'ils rivaliseraient avec l'éternité, grâce à leur immense puissance et leur très grand prix, on les voit ruinés et même écroulés sous l'effet de l'âge et d'autres avatars».

27 Comme le montre Dominique Poulot, dans «Surveiller et s'instruire» : la Révolution française et l'intelligence de l'héritage historique, op. cit. 
et pensent l'état de destruction de ce qui commence à peine à se construire ${ }^{28}$ - signe du pessimisme profond qui hante l'enthousiasme révolutionnaire.

Au plus fort de la Terreur, les révolutionnaires prennent conscience de la nécessité d'assumer l'héritage, et de conjuguer conservation et régénération. Ce tournant est marqué par le rapport de Grégoire sur le vandalisme et plus encore par l'essai de Boissy d'Anglas, publié en mars 1794 (Quelques idées sur les arts, sur la nécessité de les encourager) qui fait pour la première fois place au temps et à l'histoire : le temps peut "compléter le grand ouvrage de la régénération de l'esprit humain».

Le despotisme en expirant a laissé à la France régénérée un superbe et vaste héritage qu'elle ne saurait répudier sans honte. Il lui a restitué, pour les siècles et pour l'Univers, l'immense dépôt de toutes les connaissances humaines, le résultat de tous les talents de l'esprit, le produit de toutes les créations du génie. C'est dans ses mains que sont pour ainsi dire, réunies et fixées, comme en un seul et unique faisceau, toutes les lumières qui ont pu jaillir jusqu'ici du choc de toutes les pensées, et de l'ensemble de toutes les méditations. Elle doit donc aux nations qui lui succèderont un jour, de transmettre dans toute son intégrité cet inappréciable dépôt. Elle leur doit de ne pas arrêter, par une coupable indifférence, la marche et les progrès de l'esprit humain, et de faire pour la postérité ce que les siècles passés ont fait pour elle ${ }^{29}$.

Boissy envisage une continuité entre conservation et régénération: l'héritage (du passé), rendu à la lumière par le présent, est chargé de régénérer les arts à l'avenir ; l'héritage est au service de la transmission et du progrès des arts et des mœurs. Et dans cette transmission aux nations, la France joue un rôle crucial, puisque sa liberté nouvellement acquise lui confère la tâche d'éclairer les progrès de l'esprit humain. En outre, tout comme la régénération, la conservation est elle aussi placée

28 Ainsi le tableau d'Hubert Robert présenté au Salon de 1796, Vue imaginaire de la Grande Galerie en ruines, pendant d'un Projet d'aménagement pour la Galerie exposé au même Salon, en reprend exactement les proportions, la couleur de la pierre, mais la vide de toutes ses pièces, sauf l'Apollon du Belvédère : seule pièce intacte, devant laquelle le dessinateur tire des leçons du passé pour reconstruire le présent, comme les artistes présents à Rome puisent à la source de l'antique pour trouver l'inspiration d'un art nouveau. Le présent s'édifie sur les ruines du passé. Voir aussi le tableau de Gabriel de Saint Aubin, Vue prophétique de l'église Sainte-Geneviève pour l'an 3000 .

29 Quelques idées sur les arts, sur la nécessité de les encourager, Paris, Imprimerie Polyglotte, an II [1794], p. 4-5 (je souligne). 
sous le signe de l'instruction publique (invoquée par l'Instruction sur la manière d'inventorier, qui définit les catégories de biens à conserver ${ }^{30}$ ), et débouche sur la création.

\section{3) Régénération et création}

L'Antiquité n'est pas seulement un patrimoine mort, à conserver, mais bien un modèle à suivre, indissolublement politique et esthétique : «La capitale de la France a vu se former dans son sein des sociétés dont l'unique but est de lui donner la splendeur d'Athènes et de Rome vertueuses $^{31} »$. L'Antiquité est paradoxalement l'unique horizon du renouvellement de la société et du progrès des arts, comme le disent les références incessantes à Mengs, Winckelmann et Reynolds, les chantres du néoclassicisme : les Grecs ont tracé la «route de la perfection» (Watelet et Lévêque ${ }^{32}$ ), il n'est que de la suivre. Rares sont les voix (on le verra) qui détonnent dans ce concert unanime. Dans le Journal de Détournelle, Aux armes et aux arts!, les artistes révolutionnaires réunis en une «société populaire et républicaine des arts ${ }^{33}$ » soulignent partout le rôle moral et politique des arts : il s'agit d'invoquer l'antique pour y

30 La commission envoie aux départements en 1794 une Instruction sur la manière d'inventorier et de conserver dans toute l'étendue de la République tous les objets qui peuvent servir aux arts, aux sciences et à l'enseignement (par un antiquaire et un anatomiste), qui utilise le principe taxinomique emprunté aux sciences naturelles. La section VIII, consacrée aux «Antiquités», s'ouvre sur ce lien entre conservation et régénération : «La plupart des monuments de l'antiquité n'offrent aux sujets des despotes qu'un spectacle pénible, que des souvenirs amers, que des leçons inutiles, puisqu'ils ont si rarement le courage d'en profiter. Les peuples libres, au contraire, aiment à y voir le génie des arts soutenu par celui de la liberté. Ils y trouvent des modèles; et ce genre d'étude, qui lie la Grèce et l'Italie républicaines à la France régénérée, est un de ceux dont il importe le plus de répandre le goût et de favoriser l'enseignement.» (dans Athanase Détournelle, Aux armes et aux arts! Journal de la société populaire et républicaine des arts, Paris, Détournelle, 1794, p. 44).

31 Tribut de la société nationale des neuf scurs, prospectus, juillet 1790, p. 1, cité par Édouard Pommier, L'art de la liberté, op. cit., p. 59.

32 Encyclopédie méthodique ou Dictionnaire des arts de peinture, sculpture et gravure, Paris, Prault, 1792, article «Imitation», p. 130 : «Jusqu'à présent, entre les modernes, aucun n'a pris la route de la perfection que les anciens Grecs avaient tracée : car, depuis la renaissance des arts, on n'a eu pour but que le vrai et l'agréable, au lieu de prendre le beau pour objet».

33 Issue de l'éphémère Commune des arts, qui réunit trois cents artistes autour de David à l'automne 1789 et tente de se substituer à l'Académie en août 1793, avant d'être dissoute à l'automne. 
puiser une force de régénération pour l'avenir. Ainsi le peintre Wicar, élève de David, dans son Rapport sur les figures antiques qui sont au Muséum (1794), ne visite les salles de moulages de l'Académie que pour y invoquer avec lyrisme les «mânes des vainqueurs de Marathon et de Salamine», l'inspiration démocratique d'un art fondé sur la liberté, délivrant de la tyrannie.

Citoyens, Choisis par la société, afin de visiter la Salle des Antiques, nous nous y sommes transportés pour examiner quels seraient les objets susceptibles d'être moulés pour l'avancement des artistes, le bien général des arts, et surtout pour les régénérer, en leur faisant prendre une direction digne du faisceau de lumières qui nous entoure et de la liberté que nous avons conquise. [...] Ô Mânes des vainqueurs de Marathon, de Salamine et de Platée, nous sommes-nous écriés, en soupirant! Recevez l'hommage de jeunes artistes d'un pays où les premiers rayons de la liberté annoncent déjà à l'Univers qu'il est prêt à venger les outrages qu'une chaîne de siècles barbares a appesanti sur tout ce qui attestait votre grandeur. Recevez-en le serment solennel : ils jurent de ramasser soigneusement ces précieux débris ; ils en composeront d'éternels monuments à la gloire de leurs braves défenseurs et à la vôtre. Les Républicains, nos frères, le veulent ainsi. Vénérable Antiquité ! inspire-nous le vrai caractère, le seul digne de représenter la liberté et l'égalité, et vois déjà ce qui se passe par le mépris que nous avons pour de barbares productions, complices de la servitude et de la tyrannie et dont l'anéantissement suivrait de près le nôtre ${ }^{34}$.

Cette Grèce mythique qui hante le discours sur l'art offre le modèle intemporel d'une patrie qui honore ses grands hommes et ses artistes. En 1791, Jansen, connu surtout pour sa traduction de Winckelmann, demande à l'Assemblée la création d'une "Galerie de la liberté» au Louvre, qui immortaliserait les héros de la Révolution, car : «La liberté forme une des principales causes de la prééminence des Grecs dans l'art. (W[inckelmann], Histoire de l'art, liv. IV, ch. ${ }^{35}$ )».

Aux armes et aux arts, op. cit., p. 157-158.

35 Hendrik Jansen, Projet tendant à conserver les arts en France, Paris, Imprimerie de la société nationale des Neuf sœurs, 1791, p. 5. Voir p. 9: «Et si la ville d’Egée, en Achaïe, fit construire à ses dépens un portique pour un simple athlète plusieurs fois vainqueur, afin qu'il pût s'y exercer dans la gymnastique, oserait-on croire qu'une nation naturellement sensible et généreuse se refusât le noble plaisir d'avoir sans cesse devant les yeux les statues des illustres citoyens qui lui ont donné de grands exemples de vertu et de patriotisme ? Je me représente en idée l'immense galerie du Louvre, destinée, dit-on, à recevoir les chefs-d'œuvre de l'art des trois écoles ; devenue, sous le nom de Galerie de la liberté, le sanctuaire de l'héroïsme et du dé- 
Jansen conclut: "Que la Grèce nous serve de modèle ${ }^{36}$ ", modèle largement mythique que la Révolution prétend transformer en réalité. Ce discours est amplement développé par Boissy d'Anglas dans ses Quelques idées sur les arts (1794), expliquant que les miracles de l'art grec sont doublement dus à la liberté : un même souffle poussait les artistes à créer et les citoyens à se battre pour leur patrie, identifiée au patrimoine artistique ${ }^{37}$. La Grèce donne le modèle d'un art patriotique et moral, comme le souligne encore le sculpteur Espercieux ${ }^{38}$.

Mais la possibilité de ressusciter l'antique n'est pas aussi évidente, elle se conjugue à l'expérience d'une perte irréparable. Infirmant l'optimisme d'un Jansen, Watelet et Levêque ${ }^{39}$ adoptent un ton plus résigné, suivant l'évolution de Winckelmann lui-même dans son Histoire de l'art chez les Anciens (1764, traduit en 1789) : les circonstances présidant à l'épanouissement de l'art grec, mises en lumière dans leur

vouement patriotique. Je crois y promener mes regards sur les images des grands hommes qui ont bien mérité de la patrie, et sur une suite de tableaux, représentant les événements mémorables d'une révolution qui fera, jusqu'à la fin des siècles, l'étonnement et l'admiration de l'univers. Dans la Grèce, toute la ville qui avait vu naître un vainqueur aux grands jeux, que dis-je, la république entière, prenait part à sa gloire, et la regardait comme la plus singulière félicité qui put arriver à un mortel».

36 Ibid., p. 13 : «Je le répète, que la Grèce nous serve de modèle : soutenons le génie et récompensons les talents de nos Phidias et de nos Apelle, en les chargeant de retracer à la postérité les images de ceux dont le courage et l'éloquence nous ont rendus libres».

37 Quelques idées sur les arts, op. cit., p. 15: «Ces miracles, les Grecs les durent principalement à leurs institutions publiques, où les arts occupaient tant de place ; [...] à cet enthousiasme pour la liberté, qui est le même que celui des arts et du génie. C'étaient leurs monuments, leurs statues, leurs temples, leurs orateurs et leurs artistes, que les Grecs défendaient contre les entreprises des tyrans, et pour lesquels ils vainquirent à Salamine et à Marathon : leur patrie était cet amas de chefs-d'œuvre qui parlaient si puissamment à leur cœur [...] Comment en effet, après avoir vu le spectacle si pompeux et si touchant du vrai courage couronné par la liberté, et célébré par tous les talents, les soldats grecs n'auraient-ils pas été des héros ?»

38 Discours du sculpteur Espercieux, 2 avril 1794, dans Athanase Détournelle, Aux armes et aux arts, op. cit., p. 173 : «Les artistes représentèrent tout ce que l'imagination ardente des Grecs pouvait produire, conjointement avec l'histoire des peuples et celle des hommes qui avaient su être utiles à leur pays. L'histoire des monuments chez les Grecs serait l'histoire de ses exploits, de ses vertus et de ses superstitions».

39 Dans leur Dictionnaire des arts de peinture, sculpture et gravure, Paris, Prault, 1792, notamment aux articles «Beauté» et «Grecs». L' «Avertissement» au premier tome, paru en 1788, précise que Watelet a écrit seul jusqu'à l'article "Conférence», aidé ensuite par Lévesque et quelques autres. 
singularitée ${ }^{40}$, sont à jamais perdues pour cette raison même : «Il en va de nous comme des gens qui croient reconnaître et voir des fantômes là où il n'y a rien : le nom d'Antiquité est devenu un préjugé ${ }^{41} »$.

La perfection grecque est un sommet à la fois indépassable et éphémère, et, au-delà de sa perte inexorable, ne peut être qu'une idée, un idéal qui suscite un mélange de nostalgie et d'espérance ${ }^{42}$. Renvoyant dos-à-dos le triomphalisme et le défaitisme, Quatremère de Quincy opère la synthèse des deux positions dans ses Considérations sur les arts $d u$ dessin (début 1791), profondément influencées par Winckelmann, et dans les deux ouvrages qui répondent aux objections suscitées, la Suite et la Seconde suite aux considérations sur les arts du dessin (mai 1791) ${ }^{43}$. Pour des motifs climatiques, religieux, moraux et politiques, les arts ne sauraient redevenir ce qu'ils ont été, mais le changement de régime ouvre un immense espoir : "Le règne de la liberté doit aussi ouvrir aux arts une carrière nouvelle ${ }^{44} »$.

Encore faut-il ne pas imiter Athènes, ni «croire que, hors de ce maximum, que l'on place en Grèce avec tant de raison, il n'y eût plus que le choix entre le vice et la nullitét ${ }^{45}{ }$. Quincy tente de dépasser le niveau purement idéologique où s'était cantonné le discours révolutionnaire,

40 Au début de l'Histoire de l'art chez les anciens, trad. Huber, Paris, Barrois, 1789, t. II, livre IV, «De l'art des Grecs», p. 2: «Le principe de la supériorité des Grecs dans l'art doit être attribué au cours de différentes causes : à l'influence du climat, à la constitution politique et à leur façon de penser, ainsi qu'à la considération dont jouissaient les artistes, et à l'emploi qu'ils faisaient des arts".

41 Geschichte der Kunst der Altertums, Dresde, 1764, reprint Darmstadt, 1993, p. 393, cité par Élisabeth Décultot, Johann Joachim Winckelmann, op. cit., p. 111. La traduction de Huber, qu'il aurait été logique de citer ici, est moins percutante: «Nous sommes souvent, à cet égard, dans le cas de ceux qui, persuadés de l'existence des spectres, s'imaginent voir quelque chose là où il n'y a rien. On se prévient en faveur de tout ce qui est antique» (Johann-Joachim Winckelmann, Histoire de l'art chez les anciens, op. cit., t. III, p. 263).

42 Comme le disait déjà Chénier dans L'invention (1787-1790), v. 61-62: «Mais leurs mœurs et leurs lois, et mille autres hasards, / Rendaient leur siècle heureux plus propice aux beaux-arts».

43 Antoine Quatremère de Quincy, Considérations sur les arts du dessin, op. cit. Sur Quatremère de Quincy, voir Robert Schneider, Quatremère de Quincy et son intervention dans les arts, Paris, Hachette, 1910, et L'esthétique classique chez Quatremère de Quincy, Paris, Hachette, 1910.

44 Antoine Quatremère de Quincy, Considérations sur les arts du dessin, op. cit., p. 50-52. Dans la Suite, il salue «le règne de la liberté, l'impulsion de tous les sentiments vers un renouvellement général en tout ordre de choses».

Ibid., p. 51. 
en proposant une conception nuancée de l'imitation qui ne soit pas reproduction ni retour au même. Dans cette imitation, le génie de l'artiste joue un rôle plus grand que toutes les théories et ne dépend ni des écoles ${ }^{46}$, ni même des musées. Le révolutionnaire libéral ne partage pas la foi aveugle de ses collègues dans les pouvoirs de l'instruction et de la conservation du patrimoine. Athènes est un point de non-retour, et la France doit se rapprocher de la Grèce en restaurant un équilibre entre société et nature, école et génie. Sans aller jusqu'à une mise en perspective historique (car il refuse de considérer ce qui sépare chronologiquement l'Antiquité de la Révolution), Quincy s'oppose en tout cas à l'idée $d^{\prime}$ 'une résurrection et lui préfère le modèle $d^{\prime}$ 'une inspiration, $d$ 'une imitation consciente et réfléchie du modèle : l'avenir n'est pas une résurgence, mais un progrès des arts au service de la sociétét ${ }^{47}$.

\section{L'espace du patrimoine (Rome, Athènes, Paris)}

La régénération des arts nécessite donc une restitution du modèle antique, non seulement au sens humaniste de la restitutio temporum, mais en un sens concret et géographique : au fil de l'année 1794, dans la reprise en main qui suit la vague iconoclaste de l'hiver 1793-1794, se formule l'idée que la France, patrie de la liberté, est désormais l'héritière légitime des chefs-d'œuvre de l'art universel. Dès 1794, les victoires remportées sur le front belge font affluer à Paris quantité de tableaux; et en 1796, la campagne d'Italie semble enfin ouvrir à la France les portes des collections d'antiques qu'elle a toujours rêvé de posséder sur son $\operatorname{sol}^{48}$. À la faveur de ces conquêtes révolutionnaires, l'idée d'un patrimoine national, qui prenait forme depuis la nationalisation des biens du clergé et se traduisait par l'ouverture de musées (les chefs-d'œuvre convergeant

46 Seconde suite, 1791, p. 45 : «Nombre d'exemples m'ont fait voir que le sentiment du beau et du vrai, que les inspirations du génie, que cette incompréhensible sensibilité qui fait le talent de l'imitation, ne dépendent ni des maîtres, ni des écoles».

47 Jean Starobinski attribue à cette nostalgie du recommencement le caractère glacé de l'art néoclassique : «la lumière du commencement ne saurait resplendir dans l'instant présent qu'à condition d'être le reflet d'une origine absolue située dans le passé». Contrairement aux modes passagères, le retour au commencement doit permettre de saisir des principes éternels ; voir Jean Starobinski, 1789. Les emblèmes de la raison, Paris, Flammarion, coll. «Sur les balances du temps», 1973, p. 137.

48 Bonaparte ordonne la saisie des œuvres d'art en vertu des clauses des armistices des traités imposés aux États vaincus (armistices de Plaisance, 9 mai 1796, de Milan, 17 mai, et de Bologne, 23 juin). 
au Muséum, tandis que les musées de province accueillaient les pièces moins importantes), s'élargit aux dimensions de l'univers : le Muséum doit hériter du patrimoine universel. À l'utopie française de retrouver l'Antiquité comme moment originel du patrimoine se joint celle de devenir le lieu du patrimoine : nouvelle Rome ou nouvelle Athènes.

\section{1) Paris nouvelle Athènes et nouvelle Rome}

Certes, ce discours n'est pas nouveau : après Florence au $X V^{e}$ siècle et Rome au XVI ${ }^{\mathrm{e}}$, la France du XVII ${ }^{\mathrm{e}}$ siècle s'est aussi voulue une nouvelle Rome, dans une logique de transmissio studii. La vocation de l'Académie de France à Rome, créée par Colbert en 1666, était précisément de transporter à Paris toutes les antiques de Rome: soit sous forme de moulages, soit, le cas échéant, en se procurant directement des originaux (malgré les lois romaines interdisant les exportations). Colbert écrit à Errard, le directeur de l'Académie : «Comme nous devons faire en sorte d'avoir en France tout ce qu'il y a de plus beau en Italie, vous jugez bien qu'il est de conséquence de travailler incessamment pour y parvenir ; c'est pourquoi appliquez-vous à rechercher avec soin tout ce que vous croirez digne de nous être envoyé $e^{49}{ }$. Moyennant ces importations et ces copies, selon le Mercure galant: «On peut dire que l'Italie est en France et que Paris est une nouvelle Rome ${ }^{50} »$.

La grandeur de la France passe par la transmission et l'appropriation du modèle antique, mais sur le mode imaginaire. Les moulages suffisent, pourvu qu'ils donnent une idée complète des beautés de l'antique : ainsi la collection de moulages de Giraut est-elle particulièrement prisée, parce qu'elle a la vertu de rassembler en un lieu restreint toutes les antiques de Rome.

La Révolution franchit un pas de plus en exigeant le rapatriement des chefs-d'œuvre d'abord de Belgique, puis de Rome, par un glissement de la notion jacobine de patrie : la France n'est pas seulement la patrie de ses citoyens, mais une patrie universelle. Ce glissement s'opère entre janvier et août 1794, sensible dans le rapport de Wicar, de retour de Rome, sur les moulages d'antiques du roi et de l'Académie, en état déplorable : ces moulages en décomposition ne sont plus que les débris

49 Lettre du 6 septembre 1669, dans A. de Montaiglon, Correspondance des directeurs de l'Académie de France à Rome, Paris, Charasay frères, 1887-1908, vol. I, p. 24.

50 Le Mercure galant, 1682, cité par Francis Haskell, Pour l'amour de l'antique, op. cit., p. 58. 
de la liberté grecque expirant (janvier 1794). La première partie, déjà citée, invoquait le modèle grec comme inspirateur d'un art libre; mais réciproquement, parce qu'elle est la seule à rendre hommage à cette patrie de la liberté, la France est aussi seule digne d'hériter de ses chefsd'œuvre : la Grèce est le patrimoine spirituel de la France.

[La liberté] nous indique le lieu où jadis elle opéra tant de merveilles ; elle nous commande d'y voler et de terrasser les monstres qui souillent aujourd'hui l'heureux climat qu'elle habitait autrefois ; et de la même main, de cette main triomphante, enlever les restes de sa splendeur. C'est pour nous que le temps les a respectés, n'en doutez pas. Oui, elle nous l'assure ; il n'y a que nous qui puissions les apprécier, et nous leur élèverons des temples dignes d'eux et de leurs illustres auteurs ${ }^{51}$.

Renchérissant sur cette idée, le discours de Grégoire qui dénonce le vandalisme (31 août 1794) fait la jonction entre patrimoine national et patrimoine universel, et développe la théorie de la France patrie de la libertés $^{-2}$. Il anticipe de façon prémonitoire la conquête de l'Italie et le rapatriement des antiques au Muséum ; ce vandalisme s'autorise de la liberté nouvellement acquise, mais aussi, de manière plus discutable de la part d'un censeur du vandalisme - de celui des Romains en Grèce, invoqué à plusieurs reprises dans les journaux officiels ${ }^{53}:$ «Si nos armées victorieuses pénètrent en Italie, l'enlèvement de l'Apollon du Belvédère et de l'Hercule Farnèse serait la plus brillante conquête. C'est la Grèce qui a décoré Rome ; mais les chefs-d'œuvre des républiques grecques doivent-ils décorer le pays des esclaves ? La République française devrait être leur dernier domicile ${ }^{54} »$.

51 Athanase Détournelle, Aux armes et aux arts, op. cit., p. 157-158.

52 Grégoire, Rapport sur les destructions opérées par le vandalisme, et sur le moyen de les réprimer, 14 fructidor an II, p. 15 : "Comme nous, les arts sont enfants de la liberté ; comme nous, ils ont une patrie, et nous transmettrons ce double héritage à la postérité». Ce discours présenté devant la Convention est suivi d'un autre prononcé par Barbier, élève de David (alors en prison), le 20 septembre 1794 : «Les fruits du génie sont le patrimoine de la liberté».

53 L'argument était déjà invoqué par Sergent, peintre député à la Convention, le 25 février 1794 : «Les Romains, en dépouillant la Grèce, nous ont conservé de superbes monuments ; imitons-les» ; puis par deux articles parus dans la Décade le 29 mai 1796, qui révèlent que l'armistice de Plaisance permet à la République de conserver "quelques-uns de ces monuments des arts que l'on ne paie point, de ces chefsd'œuvre que les Romains allaient aussi conquérir dans la Grèce».

54 Grégoire, Rapport sur les destructions opérées par le vandalisme, et sur le moyen de les réprimer, op. cit., p. 27. 
Après l'arrivée des dépouilles de Rome, de Venise et d'Italie centrale (fin 1796-été 1797), leur transfert au Muséum s'accompagne d'une fête grandiose, le 9 thermidor an $\mathrm{VI}^{55}$ (27 juillet 1798), conçue sur le modèle des triomphes antiques, censée instruire le peuple et inspirer les artistes. Une procession de vingt-neuf chars portait des sentences patriotiques : «La Grèce les céda ; Rome les a perdus ; leur sort changea deux fois, il ne changera plus». La procession, accompagnée de dromadaires et de chameaux, transporte les œuvres à travers Paris, puis arrive au pied de l'autel de la Liberté au Champ de Mars, devant un buste de Brutus, le tout agrémenté de chansons et de discours. Dans son discours, le ministre François de Neufchâteau, ordonnateur de la fête, radicalise la logique développée par Wicar, Grégoire et Barbier : qu'elles soient créées dans la liberté ou dans l'oppression, les œuvres d'art n'attendaient que ce jour pour accomplir leur destinée, recevoir la consécration donnée par leur entrée au Muséum et pouvoir saluer «le siècle de la liberté» :

Mânes fameux! divins génies! dont les admirables travaux sont réunis dans cette enceinte ! répondez à la faible voix qui croit être entendue de vous : dites, lorsque vous éprouviez le tourment de la gloire, aviez-vous le pressentiment du siècle de la liberté ? Oui. C'était pour la France que vous enfantiez vos chefsd'œuvre. Enfin donc ils ont retrouvé leur destination. Réjouissez-vous, morts fameux ! vous entrez en possession de votre renommée ${ }^{56}$.

Une chanson, commandée à un auteur de vaudeville, célèbre ce transfert de propriété : «Rome n'est plus dans Rome, elle est toute à Paris» - comme si le rapatriement équivalait à une résurrection de Rome, comblant illusoirement la nostalgie humaniste devant les ruines ${ }^{57}$, en

55 La date du 9 thermidor devient une fête officielle depuis l'an III, censée conjurer le fantôme de la Terreur, et cette référence retrouve ici pleinement cette valeur, comme le rappelle le ministre François de Neufchâteau : «Voici la pompe triomphale, voici la pompe expiatoire des crimes de la tyrannie renversée le 9 thermidor».

56 Le Rédacteur, n 957, 12 thermidor an VI [30 juillet 1798] ; cité par Édouard Pommier, L'art de la liberté, op. cit., p. 455.

57 Grégoire, Troisième rapport sur le vandalisme, op. cit., p. 9 : «Parce que les pyramides d'Égypte ont été élevées par la tyrannie et pour la tyrannie, faudrait-il démolir ces monuments antiques dont un poète a dit: Leur masse indestructible a fatigué le temps. Quel est le voyageur qui n'ait pas gémi sur les débris des temples et des palais de Balbec, de Palmyre et d'Athènes ?» 
réponse à l'élégie de Du Bellay qui constatait une perte inéluctable : «Rome n'est plus ${ }^{58}$ ».

\section{2) Rome capitale des arts}

Cette voix de l'humanisme n'était pas complètement éteinte, ni obsolète : Quatremère de Quincy ${ }^{59}$, qui avait partagé les espérances révolutionnaires dans un renouveau des arts en 1791, avant d'être arrêté sous la Terreur et de devenir clandestin, réapparaît avec éclat en publiant les Lettres à Miranda en juillet $1796^{60}$, profitant de la polémique déclenchée dans les journaux par le rapatriement des antiques d'Italie ${ }^{61}$. Les Lettres sont couronnées par une pétition signée par cinquante artistes, suivie d'une contre-pétition à laquelle David donne sa caution. Contre l'idéologie révolutionnaire de l'appropriation, Quincy évoque la République des arts et des lettres instituée par les Lumières, où chaque patrie œuvre pour l'intérêt commun et le progrès général de la civilisation $^{62}$. Dépecer Rome, ce serait tuer la poule aux œufs d'or, en tarissant

58 Joachim Du Bellay, Antiquités de Rome, 1558, sonnet V, v. 5 et 12-14: «Rome n'est plus [...] ; Mais ses écrits, qui son los le plus beau / Malgré le temps arrachent du tombeau, / Font son idole errer parmi le monde». Tout au long du recueil, la destruction matérielle de Rome est compensée par son évocation magique, lui conférant une nouvelle universalité. La Rome est toujours présente aux yeux de l'humaniste, mais sous la forme d'un fantôme ou d'un fantasme, qui hante l'imaginaire par le biais de ses écrivains comme de ses ruines.

59 Quatremère de Quincy, partisan de la monarchie constitutionnelle, partage les idéaux de 1789 ; en 1791, il est député à l'Assemblée et participe au programme du Panthéon. Mais il se désolidarise du tournant radical de l'été 1792 et devient clandestin. Il profite de thermidor pour participer aux mouvements insurrectionnels du 13 vendémiaire an IV, mais condamné à mort, il se cache, puis comparaît devant le Tribunal criminel de la Seine en août 1796. Il est ensuite membre du Conseil des 500, puis, condamné à la déportation, il s'échappe en Allemagne et rentre avec l'amnistie du 18 brumaire. Voir l'introduction d'Édouard Pommier à Antoine Quatremère de Quincy, Lettres à Miranda sur le déplacement des monuments de l'art de l'Italie, éd. É. Pommier, Paris, Macula, 1989.

60 «Lettres sur le préjudice qu'occasionneraient aux arts et à la science le déplacement des monuments de l'art de l'Italie, le démembrement de ses écoles, et la spoliation de ses collections, galeries, musées, etc.», 1796 ; dans Antoine Quatremère de Quincy, Lettres à Miranda, op. cit.

61 Sur cette polémique, qui dure du 5 juin au 20 juillet 1796, voir Édouard Pommier, L'art de la liberté, op. cit.

62 Première lettre, op. cit., p. 89: «Ce sera comme membre de cette république générale des arts et des sciences, et non comme habitant de telle ou telle nation, que 
les sources archéologiques du renouveau des arts européens : «Je ne crois pas me tromper en prédisant que de toutes les causes de révolution ou de régénération qui peuvent influer sur les arts, la plus active, la plus capable d'y produire des effets d'un ordre tout nouveau, c'est cette résurrection générale de ce peuple de statues, de ce monde d'antiques dont la population s'augmente tous les jours ${ }^{63}{ }^{\prime}$.

Les mots révolution, régénération et résurrection sont autant d'allusions au discours révolutionnaire, que Quincy surprend en flagrante contradiction avec lui-même : en voulant s'approprier le patrimoine antique, la Révolution le détruit et se prive de ses sources de régénération. Le butin romain, une fois éparpillé entre les musées d'Europe, perdrait toute sa vertu inspiratrice et instructive ${ }^{64}$. Rome est le seul musée du monde, l'unique lieu du patrimoine universel : «le pays est lui-même le muséum». Pour cet humaniste, le site entier de Rome évoque le climat de la virtus antique, les œuvres sont inséparables de leur ciel, de leur climat, et des autres œuvres auxquelles elles répondent. D'où sa réticence face à l'idée même de musée, qui dénature l'œuvre en la séparant de son contexte, et surtout, la prive de son utilité morale ${ }^{65}$; le trésor de l'Antiquité est inamovible, inséparable de son lieu de naissance, de son ciel ; et c'est aux artistes et aux amateurs de se déplacer, d'accomplir le pèlerinage jusqu'aux racines de la civilisation, comme ils le font depuis la Renaissance. Rome est la seule école de l'antique ${ }^{66}$.

je discuterai cet intérêt que toutes les parties ont à la conservation du tout. Quel est-il cet intérêt? C'est celui de la civilisation, du perfectionnement des moyens de bonheur et de plaisir, de l'avancement et des progrès de l'instruction et de la raison, de l'amélioration enfin de l'espèce humaine. Tout ce qui peut concourir à cette fin appartient à tous les peuples; nul n'a le droit de se l'approprier ou d'en disposer arbitrairement».

Deuxième lettre, op. cit., p. 96-97.

64 Quatrième lettre, op. cit., p. 114-115.

65 Idée reprise dans les Considérations morales sur la destination des ouvrages de l'art, Paris, Crapelet, 1815, p. 42-43: «La manie des collections, et l'abus des ouvrages qu'on destinerait à les grossir, ont pour inconvénient principal, d'enlever aux arts ce qui est leur légitime patrimoine, de les déshériter, en quelque sorte, en les bannissant de tous les emplois politiques, religieux et moraux.»

66 Septième lettre, op. cit., p. 136: «Le principe même, en vertu duquel chaque nation veut augmenter ses collections pour offrir à ses élèves l'avantage des parallèles nombreux, est précisément celui qui doit empêcher d'appauvrir de plus en plus le centre général de tous les points d'étude et de comparaison; que la vraie manière de s'enrichir en ce genre serait de rapporter au centre, de rendre enfin plutôt que de prendre ; que fractionner l'enseignement, tronquer les collections et morceler les galeries de Rome et de l'Italie, ce n'est pas propager, mais disperser les Lumières ; 
Dans la même veine, l'article «artiste» de Watelet évoquait la soif qui pousse l'artiste à Rome, seul lieu de ses aspirations, parce que par Rome passe la «chaîne d'or» qui nous relie à la Grèce ${ }^{67}$ (il n'y a donc pas contradiction, mais complémentarité, entre les deux modèles antiques) : «Le jour, la nuit, dans ses rêves, il se croit déjà parvenu au but de ses désirs : il est à Rome ; il court se prosterner devant Apollon au Belvédère, devant Raphaël au Vatican». Ou pour Gœthe, renchérissant sur Winckelmann : " Rome est, selon moi, la grande école pour le monde entier, et moi aussi, je suis éclairé et éprouvé". Ces paroles s'accordent exactement avec ma manière d'observer ici, et certainement, on n'a hors de Rome aucune idée de l'enseignement qu'on y reçoit. Il faut, pour ainsi dire, naître de nouveau ${ }^{68} "$.

Rome est l'unique lieu de l'initiation artistique, et non pas un Louvre qui se proclame arbitrairement «l'école de l'univers». En voulant s'approprier le patrimoine romain, les révolutionnaires ont aboli la géographie, comme ils avaient aboli l'histoire en prétendant renouer directement avec les commencements : autant d'utopies et d'uchronies propres à l'idéologie révolutionnaire. Car c'est par une révolution, spatiale et temporelle, que Rome se retrouve à Paris, et que Rome, qui était partout appelée "Capitale des Arts», que ce soit dans l'article "Artiste» de Watelet ou dans le Journal en Italie de Gœthe, se voit ravir ce titre par Paris, dans l'essai de Boissy d'Anglas déjà cité (1794) :

ce n'est pas étendre l'instruction, mais la décomposer; ce n'est pas la changer de place, mais l'exiler ; ce n'est pas développer l'arbre, mais dépecer ses branches ; ce n'est pas disséminer les principes de vie, mais enfouir comme en Egypte en autant de tombeaux que de villes les membres d'Isis.»

67 Dictionnaire des arts de peinture, sculpture et gravure, op. cit., article «Artiste», p. 137 : "Je veux que suffisamment muni de connaissances théoriques, de lectures utiles, d'habitude de voir et de sentir, il se soit plus d'une fois écrié : “Ô Italie, ô Rome, lieux désirés par tous ceux qu'embrase l'amour des arts, lieux où se trouve encore aujourd'hui cette chaîne d'or attachée à la Grèce, étendue jusqu'à l'Italie, et de là dans nos climats, où les chaînons usés menacent de nous échapper ! Quand serai-je digne de vous parcourir? Quand pourrai-je recueillir à mon tour quelqu'un de ces fruits précieux qui communiquent l'immortalité ?"»

68 Johann W. Gœthe, Voyage en Italie, éd. Jean Lacoste, Paris, Bartillat, 2003, p. 172-173. On peut citer aussi la pensée de Gœthe déniant la possibilité d'un art patriotique, citée dans Anton Raphael Mengs, Pensées sur la beauté et sur le goût dans la peinture, Paris, ENSBA, coll. «Beaux-arts histoire», 2000, avec une Préface de Fabienne Brugère et Denise Modigliani, p. 7: «Il n'y a pas d'art patriotique et pas de science patriotique. Tous deux appartiennent, comme tout bien supérieur, à l'ensemble du monde et ne peuvent être favorisés que par la libre interaction universelle de tous les vivants d'une époque, en considérant toujours ce qui nous reste du passé et qui nous est connu». 
Que Paris donc soit la capitale des arts : qu'il retrouve, dans l'avantage inestimable d'être l'asile de toutes les connaissances humaines et le dépôt de tous les trésors de l'esprit, une nouvelle splendeur plus éclatante que celle qu'il retirait de son luxe, de ses plaisirs factices et de tous les abus qui formaient, en quelque sorte, sa dot et son patrimoine ; il doit être l'école de l'univers, la métropole de la science humaine, et exercer sur le reste du monde cet empire irrésistible de $l^{\prime}$ instruction et du savoir. [...] C'est à Paris, sans doute, qu'il faut établir le dépôt sacré de toutes les connaissances humaines, et la réunion des résultats les plus précieux de l'imagination et du génie : c'est à Paris qu'il faut rassembler tous les monuments des sciences et des arts, dont l'ensemble est si nécessaire à leur perfectionnement ${ }^{69} \ldots$

\section{Canon, imitation, invention}

Pour Boissy d'Anglas comme pour la plupart des révolutionnaires, la conservation sert en permanence de socle à la création, et le rapatriement est légitimé non seulement par la «libération» des arts opprimés dans les nations despotiques, mais par la nécessité d'offrir des modèles aux artistes. L'institution muséale, destinée en priorité aux artistes, forme un trait d'union entre le passé et le futur, et le legs des générations passées aux générations futures consiste bien moins à fixer le patrimoine qu'à le faire revivre dans une création continuée. En quelques années, le style néoclassique devient le langage officiel de l'art révolutionnaire, corroborant l'idée que la rupture est conçue comme une renaissance, un retour aux commencements, qu'il faut bien distinguer des premiers retours que furent la Renaissance et le classicisme.

\section{1) Permanence des exempla}

En effet, à première vue, les écrits révolutionnaires perpétuent la tradition des exempla héritée des guides de voyages romains : dès le $\mathrm{XVI}^{\mathrm{e}}$ siècle, l'itinéraire du pèlerin à Rome passe par un certain nombre de lieux attendus, la cour du Belvédère, les jardins Médicis, les collections Farnèse, Borghèse, etc., et se traduit par la déclinaison immuable et quasi invocatoire du même corpus de statues antiques, censées conte- 
nir l'essence du beau éternel ${ }^{70}$; d'où l'importance de les copier, ce qui est fait d'abord artisanalement, puis en série, de manière de plus en plus répétitive. Cette liste passe des guides de voyage aux traités d'art, italiens (au XVI ${ }^{\mathrm{e}}$ ) puis français (au XVII $)$, et forme encore le credo des antiquaires des Lumières, qui s'enthousiasment pour l'antique : Caylus, Cochin, $\mathrm{Webb}^{71}$, Watelet ${ }^{72}$, Winckelmann ${ }^{73}$, Quatremère de Quincy prennent plaisir à décliner, à énumérer le patrimoine antique ${ }^{74}$. Le corpus paraît à tel point immuable que Winckelmann, dans son Histoire de l'art chez les Anciens, qui tente pour la première fois d'instaurer une chronologie et une hiérarchie des statues antiques, ne semble pourtant aspirer qu'à justifier l'exemplarité des œuvres canoniques, au point qu'il les attribue toutes faussement à des sculpteurs grecs de l'époque de Phidias, ignorant - ou préférant ignorer - que la plupart sont des copies romaines.

Ces exempla constituent une liste canonique au sens propre du terme, puisqu'ils renferment les canons de la beauté, et doivent permettre aux artistes de se faire une idée de la belle nature, d'apprendre sur eux les bonnes proportions pour ensuite corriger le modèle vivant qui n'en est qu'une version dégradée. Toute création est imitation et émulation, comme le dit Colbert au directeur de l'Académie en 1682 : «Faites achever avec diligence et amour les ouvrages qui sont commencés, et prenez garde surtout qu'il ne sorte aucun ouvrage de l'Académie qui ne soit dans une très grande perfection, et même, s'il est possible, plus

70 Je me permets de renvoyer sur ce point à mon article, «Rome, un lieu commun ? Usage et usure du topos dans les récits des voyageurs français à Rome au XVII siècle», dans Revue d'Histoire Littéraire de la France, 104, 3, automne 2004, 597-620.

71 Webb, Enquête sur les beautés de la peinture, Paris, Briasson, 1765, p. 44 et 48 : «Voyez les belles proportions, la force du style du Laocoon et du Gladiateur, l'expression énergique, le divin caractère de l'Apollon, les grâces élégantes de la Vénus de Médicis ! [l'auteur cite ensuite tous les exempla : Hercule Farnèse, Niobé] Le Jupiter de Phidias et l'Hercule de Lysippe sont deux exemples de la supériorité du génie des Grecs ; et l'on peut dire que, s'ils ont perfectionné la nature, c'est moins en abandonnant ses proportions, qu'en enchérissant sur les idées qu'elle leur fournissait».

72 Dictionnaire des arts de peinture, sculpture et gravure, op. cit., article "Antique», t. I, p. 83-84 : «L'Apollon, la Vénus Médicis, le Torse, le Laocoon, le Gladiateur toujours admirés depuis qu'ils ont été découverts dans les ruines des palais ou des temples, sont proposés de génération en génération à l'observation, à l'étude, et à l'imitation des peintres et des sculpteurs».

73 Dans son Histoire de l'art chez les anciens, Winckelmann examine les différentes beautés des statues canoniques.

74 Sur ce chapitre, voir encore Chantal Grell, Le dix-huitième siècle et l'Antiquité en France, op. cit. 
parfait que l'antique ${ }^{75} »$. Suit une liste de plusieurs pages des antiques copiées en série par les pensionnaires, qui seront reproduites dans les jardins de Versailles ${ }^{76}$. La même liste se retrouve dans $l^{\prime} E n c y c l o p e ́ d i e:$ "Les figures antiques que nous possédons, telles que l'Hercule Farnèse, l'Antinoüs, l'Apollon, la Vénus de Médicis, le Laocoon, le Torse, tant d'autres offrent aux artistes les moyens de connaître les belles formes et l'élégance des proportions ${ }^{77}$ ». Elle est de nouveau en 1794 dans le rapport de Wicar sur le musée des antiques, qui emprunte le lyrisme de Winckelmann pour décrire le $\operatorname{Laocoon}^{78}$ : bref, la Révolution ne change pas ces références canoniques. La seule critique vient de Quatremère de Quincy, qui conteste le principe même de la liste dans une perspective historiciste : le patrimoine est un tout indissociable, vaut en lui-même comme témoignage du passé, et l'élection d'une série d'exempla est une démarche artificielle, un camouflage idéologique de l'histoire de l'art, où le grand voisine avec le médiocre. À l'inverse, un panorama fidèle permettra à l'élève de confronter qualités et défauts des différents artistes et d'établir une échelle de valeurs, démarche impossible entre des œuvres d'excellence ${ }^{79}$.

7520 juillet 1682, dans A. de Montaiglon, Correspondance des directeurs de l'Académie de France à Rome, op. cit., vol. I, p. 116.

76 Ibid., p. 129-134: 6 déc. 1684, «Inventaire général de l'Académie [...] de toutes les figures et reliefs de plattre que l'on a moulé sur les plus belles antiques de Rome, des figures antiques que les élèves copient».

77 Encyclopédie, Recueil de planches sur les sciences, les arts libéraux et les arts mécaniques avec leur explication, II, 2, 1763, art. «Dessein», op. cit., 1967, vol. 24, p. 2-3.

78 Rapport sur les figures antiques qui sont au Muséum, dans Aux armes et aux arts, op. cit., p. 160 : «Nous proposons donc les restes précieux de l'Antiquité, qui nous ont paru mériter d'être moulés pour remplir l'intention de la Société, qui sont : Le Gladiateur Borghèse. / Les Lutteurs, de Florence. / Ganimède, de Florence. / Castor et Pollux, d'Espagne / Discobolo, du Vatican. / Petit Niobé, un genou en terre. / Pétus et Aris. [...] / Le Nil et son pendant, du Museum du Pape. [...] / Enfant qui se tire une épine du pied, du Capitole. / Gladiateur mourant, du Capitole. / Tête de Sénèque [etc.]».

79 Voir par exemple la sixième des Lettres à Miranda (1796), op. cit., p. 128 : «Ce n'est pas même toujours dans les plus excellents ouvrages des grands maîtres que l'on parvient le plus facilement à découvrir le secret de leur manière ; là, tout l'échafaudage de l'art est détruit ou caché ; on y trouve souvent plus à admirer qu'à reprendre ; aussi les collections qui ne nous présentent qu'un choix de chefs-d'œuvre de chaque maître sont quelquefois plus désespérantes qu'instructives pour les élèves». Ou encore les Considérations morales sur la destination des ouvrages de l'art, Paris, Crapelet, 1815, p. 43-44: «Si les collections pouvaient ne présenter qu'un recueil choisi de ce qu'il y a de plus parfait, on ne craint pas de dire encore qu'un tel rassemblement, en devenant excessif, produirait sur l'esprit du public un effet d'un 
L'imitation reste la voie royale de l'invention, comme on le voit dans les articles «imitation» de l'Encyclopédie par Jaucourt ${ }^{80}$ et du Dictionnaire de Watelet (qui la distingue toujours de la pure copie) ; chez Saint-Victor, dans son Musée des Antiques, citant Quintilien sur la nécessité de toujours combiner l'imitation et l'invention ${ }^{81}$; ou encore chez Quincy : «L'imitation, dans les arts du dessin, ne saurait jamais se séparer de $l^{\prime}$ invention ${ }^{82} \gg$.

À ses yeux, il n'existe aucune contradiction entre les deux principes, selon un raisonnement dialectique issu de Winckelmann dont la célèbre phrase, "La seule manière pour nous de devenir grands, et même, si cela se peut, inimitables, c'est d'imiter les Anciens», donne le modèle $\mathrm{d}^{\prime}$ une imitation non servile ${ }^{83}$, dans la lignée des Modernes de la Querelle ou des instructions de Colbert ${ }^{84}$. L'historien creuse un paradoxe :

autre genre, également désavantageux aux arts. C'est que sur ce point, comme sur tout autre, l'excès des jouissances en amortirait le sentiment. Au moral ainsi qu'au physique, le goût s'émousse par l'habitude de sensations trop vives ou trop fortes. Celui qui ne verra plus qu'une élite de chefs-d'œuvre, perdra bientôt le sentiment de leur valeur".

80 "Ainsi l'imitation née de la lecture continuelle des bons originaux, inspire le goût, étend le génie, et perfectionne les talents [...] Ne rougissons donc pas de consulter des guides habiles, toujours prêts à nous conduire. [...] nous pouvons les atteindre, en les prenant pour modèles et pour rivaux dans nos imitations ; si nous ne les atteignons pas, du moins nous pouvons nous en approcher [...] Concluons que c'est à l'imitation que les modernes doivent leur gloire, et que c'est de cette même imitation que les anciens ont tiré leur grandeur [d. J.]». Louis de Jaucourt, article «Imitation", dans Diderot et d'Alembert (dir.), Encyclopédie ou Dictionnaire raisonné des sciences, des arts et des métiers, par une Société de gens de lettres, Paris, édition en fac-similé, Stuggart Bad Cannstatt, Friedrich Fronsmann Verlag, 1966, t. VIII, p. 568.

81 J.-B. de Saint-Victor (et P. Bouillon, peintre), Musée des antiques, Paris, Didot, 1823, p. 7 (l'auteur paraphrase Quintilien, Institution oratoire, $X, 2$ ).

82 Antoine Quatremère de Quincy, Considérations sur les arts du dessin, op. cit., introduction, p. xi.

83 Dans Erinnerung über die Betrachtung der Werke der Kunst (1759), il distingue imitation (die Nachahmung) et simple copie (das Nachmachen): «Sous le terme copie, j'entends le calque servile [knechtische Folge]. Dans l'imitation au contraire, l'objet imité, lorsqu'il l'est avec intelligence, peut devenir pour ainsi dire une nouvelle nature et constituer quelque chose d'autonome» (cité par Élisabeth Décultot, Johann Joachim Winckelmann, op. cit., II ${ }^{\mathrm{e}}$ partie, chap. 2, p. 110).

84 Ainsi, pour Mengs, le modèle antique est une voie d'accès privilégiée à la nature. Voir Anton Raphael Mengs, Pensées sur la beauté et sur le goût dans la peinture, op. cit., p. 57 : «Mais si l'on veut trouver le mode d'imitation approprié, on ne doit pas abuser de celle-ci, mais réfléchir sur les œuvres des grands maîtres et en juger de la même façon qu'eux-mêmes ont jugé de la nature, autrement on ne connaîtra que 
comment imiter un modèle insurpassable ? En imitant non les œuvres mêmes, leurs canons ou leurs sujets, mais en retrouvant les principes de leur conception : une imitation procédant par abstraction et synthèse jusqu'à la beauté idéale ${ }^{85}$. Par ce paradoxe, Winckelmann dépasse la conception classique de l'imitation vers une réflexion sur l'originalité et les virtualités de l'origine, c'est-à-dire sur la manière de s'approprier une origine par définition irreproductible ${ }^{86}$. Il reprend et déplace le principe éducatif de l'exemplum, en juxtaposant l'esthétique de la belle nature, apparemment inchangée, à une approche de type historiciste, qui insiste sur les conditions spécifiques du développement de chaque art. Précisément, la question de Winckelmann devient d'une grande actualité sous la Révolution, au point qu'en 1805, l'Institut, soucieux de prendre des mesures concrètes pour régénérer les arts, lance un concours sur la question : "Quelles ont été les causes de la perfection de la sculpture antique, et quels seraient les moyens d'y atteindre?»

\section{2) Critique et dépassement du modèle}

À voir cette permanence de l'idéal antique, unique horizon de la création artistique, on pourrait croire que rien n'a changé depuis les siècles d'Auguste et de Louis XIV, et qu'on a conservé l'idée classique d'une transmission de canons intemporels. Mais le propre du discours révolutionnaire est qu'il entretient avec le modèle antique des liens conjointement plus forts et plus critiques, ou plutôt qu'il conjugue paradoxalement l'imitation et le rejet, tant en matière esthétique que politique. Comme toujours, il s'agit de faire table rase des instances assurant la transmission des modèles (en l'occurrence, les Académies),

l'écorce des choses, et l'on n'apprendra point à saisir la cause de la beauté dans leurs œuvres».

85 Sur la conception winckelmannienne de l'imitation, on consultera, outre l'ouvrage d'Élisabeth Décultot, le colloque déjà cité, Winckelmann et le retour à l'antique, notamment l'article de Gérard Raulet, «Winckelmann, un moderne chez les Anciens", 97-110 : G. Raulet montre comment Winckelmann se tourne vers l'Antiquité pour fonder une esthétique moderne, qu'il n'a pas les moyens conceptuels de formuler autrement.

86 Comme l'explique Élisabeth Décultot, Winckelmann est de plus en plus gêné par le concept d'imitation, affirmé en 1755 , et le remet en cause dès 1759 , et plus radicalement dans la Geschichte en 1764 : parmi les quatre périodes de l'art grec, la quatrième, la décadence, a l'apanage de l'imitation. La Geschichte défait le lien tissé par les Gedanken entre originalité et imitation. 
pour mieux ressusciter l'esprit du modèle à travers son adaptation nationale et patriotique. Le geste créateur n'est pas conçu comme un hommage (servile ou non) rendu au passé, mais comme sa réinvention active tournée vers l'avenir, de sorte que le patrimoine est moins transmis que complété et radicalement refondé.

Ainsi, David développe devant la Convention un discours hostile aux Académies - dont Quatremère de Quincy avait montré l'utilité deux ans plus tôt ${ }^{87}$ - et obtient leur suppression le 8 août 1793 . De plus, ce discours est relayé par bien d'autres déclarations prônant l'émancipation du modèle. Les sujets mythologiques, bons à décorer les boudoirs des princes, doivent être remplacés par des sujets d'histoire nationale :

Que de faits héroïques se passent sous nos yeux qui rivalisent avec tout ce que les Républiques d'Athènes et de Lacédémone peuvent nous offrir de plus merveilleux! En ce moment où nos armées victorieuses rappellent le courage et l'énergie républicaine des vainqueurs des Perses, pourquoi n'égalerions-nous pas aussi les chefs-d'œuvre jusqu'à présent inimitables des artistes leurs contemporains ${ }^{88}$ ?

Comme on voit, toute innovation est conçue en référence au modèle antique : c'est parce que l'histoire de la Révolution est digne d'être comparée à celle des Républiques grecques qu'elle peut fournir de dignes sujets de tableaux d'histoire; et ce discours va s'amplifiant sous le Directoire, où les sujets patriotiques sont toujours prônés en référence au patriotisme grec ${ }^{89}$. C'est seulement en réincarnant l'esprit grec que le peintre peut s'affranchir de la répétition des sujets grecs. Cette répé-

87 Dans ses Considérations sur l'art $d u$ dessin de 1791 (citées plus haut), Quincy démontre l'utilité des institutions académiques comme pivot d'un système d'encouragement public des «arts du dessin» (peinture, sculpture, architecture), dans une perspective héritée de Colbert.

88 «Discours prononcé à l'occasion de la plantation de l'arbre de la liberté, par le citoyen Lebrun (Jacques)", dans Athanase Détournelle, Aux armes et aux arts, op. cit., p. 190.

89 Voir Heurtault de Lamerville, Rapport sur les écoles spéciales de peinture, de sculpture et d'architecture, Paris, an VI, cité par Édouard Pommier, L'art de la liberté, op. cit., p. 268-269: «Quel effet ne doivent pas avoir produit dans les siècles les statues de Miltiade, d'Aristide et de Thémistocle ? Romains, ce furent vos modèles. Nous-mêmes, si nous étions jamais réduits (ce qui est impossible) à ranimer l'héroïsme de nos armées indomptables, quel stimulant plus actif pourrions-nous imaginer que de multiplier à leurs yeux les images de nos grands généraux, surtout ceux qui ont si souvent conduit nos phalanges à la victoire ? Qui sait si Léonidas n'excita pas le courage de Hoche, de Marceau, de Dugommier?» 
tition serait non seulement une fuite timorée vers des sujets obsolètes, mais une trahison à la patrie, comme le suggèrent ces vers de mirliton, plus crédibles dans leur satire que par le programme qu'ils proposent :

Réponds ! «Non, me dis-tu, ces tableaux ne sont rien ; / Il me faut un sujet hébreu, grec ou troyen. / Je veux le bouclier, la toge, la tunique / Le brodequin, le casque et la casaque antique. [...] Va, ce langage altier n'est qu'une perfidie ; / Tu caches, sous ces mots, l'horreur de la patrie ; / Si ton cœur, franchement, aimait la liberté, / Tu peindrais son triomphe avec avidité. / Tu ne vanterais plus ta mascarade antique ; / Chacun dessinerait d'après la République [...] Sans dédaigner les traits de la caduque histoire, / Le peintre citoyen marcherait à sa gloire ${ }^{90}{ }$.

Cette critique n'atteint pas seulement le sujet, mais aussi le processus même de l'imitation. La théorie du beau idéal, que Winckelmann et Mengs développent à partir de présupposés classiques, commence à être remise en question au nom de principes naturalistes. Même Watelet trahit sa lassitude de l'anticomanie ${ }^{91}$ et dénonce les effets pervers de cette imitation effrénée, qui empêche l'élève de voir avec ses propres yeux ; pour l'élève moyennement doué, mieux vaut la nature que le modèle antique. De même, Quatremère de Quincy, dans ses projets de rénovation de l'Académie qui prévoient une galerie de moulages antiques, suivant la tradition de Vasari et de Colbert, signale pourtant «l'abus de l'étude du modèle» : cette étude ne doit servir que·de correc-

90 Honoré de Balzac, «Épitre à ceux qui nuisent aux arts, en dénigrant les différents imitateurs de la nature», cité par Édouard Pommier, L'art de la liberté, op. cit., p. 335.

91 Dictionnaire des arts de peinture, sculpture et gravure, op. cit., article "Antique», t. I, p. 84 : «L'on dit et l'on répète sans cesse à la jeunesse qui court en Italie chercher avec avidité des talents qu'on n'y trouve point, si l'on en porte en soi les semences : Observez, étudiez, copiez l'antique ; pénétrez-vous de l'antique. L'antique est le modèle de la beauté sublime, du beau idéal, perfection extrême que les Grecs ont atteint par l'impulsion du génie, et que nous devons poursuivre par une jalouse et noble émulation de leurs succès. Enfin, l'on insiste encore en disant : $\mathrm{Si}$ vous vous écartez de l'antique, vous ferez rétrograder l'art. [Mais certains élèves n'ont pas ce penchant à la beauté idéale]. L'étude obstinée de l'antique leur convient moins que l'observation et l'imitation de la simple nature, choisie et rectifiée par des réflexions et des comparaisons habituelles. [...] la poursuite de perfections surnaturelles lui ferait manquer les vérités aimables que présente la simple nature. / Ce n'est pas le seul inconvénient qu'il y ait à craindre, surtout pour les peintres ; car l'imitation trop continuelle des statues antiques, ou des figures moulées sur elles, peut produire une affectation de formes qui rappelleraient les statues, sans offrir leurs véritables beautés». 
tif à l'observation de la nature, qui est la "grande cause de la supériorité des Grecs ${ }^{92}$ ».

Ainsi la critique de l'idéalisme effréné de l'esthétique néoclassique apparait-elle comme le seul moyen de se défaire d'une étouffante exemplarité. Car si les Grecs ont atteint un sommet insurpassable de l'art, ce n'est pas par la copie que les Français rivaliseront avec eux. En revanche, si leur supériorité consiste dans une méthode d'observation de la nature, alors les Français en sont tout aussi capables. C'est la réponse que fournit Émeric-David à la question posée par l'Institut en 1805 : Quelles ont été les causes de la perfection de la sculpture antique, et quels seraient les moyens d'y atteindre? Ses Recherches sur l'art statuaire, primées au concours de l'Institut, deviennent vite une référence : il y affirme explicitement - pour la première fois - que la grandeur de l'art grec consiste non dans la recherche de la beauté idéale, mais dans le naturalisme $^{93}$. Et de renvoyer dos-à-dos Mengs, Winckelmann et tous les tenants de l'esthétique idéaliste, qui rêvaient de ressusciter une Antiquité mythique ${ }^{94}$. Seule cette attitude iconoclaste permet de libérer les artistes de la culpabilité et du défaitisme qui hantent le discours sur l'art : «Il serait également indigne de nous, et de désespérer sans motifs d'atteindre à la perfection de l'antique, et de chercher à nous justifier de notre infériorité par des difficultés exagérées ${ }^{95} \%$.

Une nouvelle distance critique s'instaure face au modèle grec, qui impose de nouvelles voies à l'imitation : non pas un canon de beauté intemporel, mais un juste rapport à la nature ; non pas un corpus de sujets, mais le principe de sujets patriotiques et nationaux; non pas la

92 Quatremère de Quincy, Considérations sur les arts du dessin, op. cit., p. 124-126.

93 Recherches sur l'art statuaire considéré chez les anciens et chez les modernes [...], op. cit., p. 236-240 : «Si l'on considère l'ordre des études, il faut chercher la vérité de l'imitation avant la beauté des formes [...]. Imiter, c'est l'art ; imiter ce qui est beau, après l'avoir choisi, c'est l'art éclairé des lumières du goût ; imiter ce qui est beau, grand et expressif tout à la fois, c'est l'art guidé par le goût et par la philosophie ; mais imiter enfin, imiter avec fidélité, c'est l'art dans son essence même. Il nous semble aujourd'hui que pour louer dignement nos chefs-d'œuvre, nous devions y voir des formes surnaturelles. Nous vantons l'idéal de la beauté, l'idéal de l'expression. Les Grecs étaient plus simples ; c'est la vérité qui, la première, obtenait toujours leurs éloges».

94 De même, il refuse d'attribuer la supériorité des Grecs aux motifs traditionnellement invoqués : climat, régime politique, religion, habitude de voir le nu ou beauté supérieure des Grecs. L'essor des arts est plutôt dû au soutien du gouvernement, qui leur attribue un rôle moral et édifiant dans la cité, ce qui permet aux artistes de perpétuer une tradition ininterrompue.

95 Recherches sur l'art statuaire, op. cit., p. 18. 
copie servile de modèles canoniques, mais l'alliance de la règle et du génie. L'imitation n'est plus entendue comme restitution ni comme résurrection, mais bien comme une invention : l'invention d'un «art de la libertés6».

\section{EMMANUELLE HÉNIN}

Université de Reims

96 Pour reprendre le titre de l'ouvrage de Pommier, abondamment cité ici. 